\title{
LA VIDA EN DIRECTO O LA FALACIA DE GRAN HERMANO: LA REPRESENTACIÓN DRAMÁTICA EN EL POST-REALITY TELEVISIVO
}

\section{Isabel Menéndez Menéndez}

Investigadora de la Universidad de Oviedo

La televisión ha variado sustancialmente desde su origen; creada como una innovación tecnológica, cuyo uso no estaba definido, tenía muy poco que ver con el instrumento de comunicación social que es hoy. En España, con la llegada de la televisión privada en 1988, el modelo generalista iba a sufrir una transformación radical cuando comienza a preocuparse por el mercado, por los índices de audiencia y por la rentabilidad. Los nuevos parámetros de la televisión van a ser otros, ya que las nuevas tecnologías, el mercado - con su lucha por las audiencias-y las decisiones políticas van a configurar el nuevo modelo televisivo que se impone en España en la década de los noventa. La gran transformación, una vez desaparecida la tutela que el propio Estado ejercía sobre la televisión, será ese nuevo marco en el cual es el mercado quien organiza la televisión. En cuanto al propio contenido, e influenciado por esos nuevos parámetros de rentabilidad, vamos a asistir al nacimiento de una nueva relación entre la televisión y los espectadores. 
La televisión se va a convertir en un aparato semiótico que construye y dota de significado a su contenido. Posee la facultad de ofrecer los elementos a través de los cuales las personas construyen su percepción de la realidad. Los agentes de socialización tradicionales, familia y escuela, se complementan con las imágenes y modelos que ofrecen los medios de comunicación y, especialmente, con lo ofrecido a través de la televisión (Vilches, 1993; Ramonet, 2000).

A través de los medios se refuerzan los modelos, presentando unos concretos (los dominantes) frente a los demás, seleccionando una realidad como la ideal. Posteriormente, los valores que se ofrecen desde los medios se asocian con productos o con servicios que los refuerzan (lo que favorece un consumo determinado) y el resultado es la existencia de una conciencia que no cuestiona la percepción de que aquello que aparece en los medios es la realidad; una concepción del aparato televisivo como espejo de la realidad.

Tal y como dice la filósofa Amelia Valcárcel, el programa Gran Hermano, del que hablaremos más adelante, no es reflejo de la sociedad, ni mucho menos. Opina que nada que se hace delante de una cámara es espejo de nada ${ }^{1}$. La idea de la televisión como reflejo de la realidad es la equivocada. Otra cosa es que sea capaz de crear una realidad concreta. Como señala la profesora Margarita Ledo, se trata de una sustitución de la realidad, lo que para ella puede constituir una falsificación del territorio real por el territorio informativo (Ledo, 1987: 5).

Efectivamente, los medios de comunicación deciden cual es la realidad que van a ofrecer desde el momento en que efectúan una labor de selección de determinados fragmentos de la realidad para ofrecerlos al público. Pero no debemos olvidar que existen otros, tan válidos como los anteriores, que no han sido reflejados y que no por eso son inexistentes o falaces: la realidad ofrecida por los medios de comunicación no es la única, constituye una parte ínfima de la realidad social; se realiza una selección de la realidad que se convertirá en una construcción ideológica. Porque los medios forman opinión, tanto en los procesos de información como en los de entretenimiento.

Abordaremos ahora el concurso Gran Hermano, nuevo producto que se ofreció como una experiencia de vida en directo e incluso como experimento sociológico, falacia que intentaremos desmontar ya que, para nosotros, está directamente relacionado con la representación teatral, aunque sea utilizando elementos transgresores respecto a la obra de teatro convencional.

Gran Hermano aparece en una televisión que se enfrenta a parámetros distintos, como ya hemos explicado. El programa presenta, en primer lugar, un

\footnotetext{
1 Entrevista publicada en el diario La Nueva España, el 6 de mayo de 2001.
} 
problema de definición pues su formato no se corresponde estrictamente con ninguno de los existentes. Gustavo Bueno (2000) utiliza serie para referirse a él, concepto que implica un principio de repetición que no aparece como característica intrínseca del producto. Por otra parte, es importante no perder de vista que es un producto que, formalmente, se ofrece como un concurso. Se trata de una competición en la que participa un número determinado de participantes que intentan conseguir un premio en metálico. Por tanto, se podría decir, sin temor a equivocarse, que se trata de un concurso televisivo. Lo que ocurre es que sus características definitorias están relacionadas con toda una serie de elementos que no tienen nada que ver con el concurso tradicional y sí con otros formatos.

La ficha técnica del concurso Gran Hermano es la siguiente:

1. Identificación del programa de referencia:

1.1. Título: Gran Hermano.

1.2. Fecha de difusión: año 2000.

1.3. Tiempo/hora de programación: se ofrecen varios bloques diarios, siendo los más importantes los que se emiten en prime time (horario de máxima audiencia) y los resúmenes semanales dentro de un programa de apoyo. Así mismo, se puede seguir durante las 24 horas, a través de las plataformas digitales, mientras que la cadena productora del programa realiza una estrategia de difusión constante utilizando los espacios de mayor audiencia de su programación. Por último, se elabora todo un universo de merchadising, con revistas, vídeos, juegos, páginas de Internet y otros soportes que refuerzan que el producto esté en la opinión pública durante todo el tiempo, que sea el tema de conversación y el programa de moda. La difusión será ininterrumpida durante más de tres meses.

1.4. Contenidolasunto: concurso con un premio millonario que obtendrá la persona que se vaya en último lugar. Diez concursantes, que no se conocen entre sí, son introducidos en una casa construida a tal efecto, donde las cámaras de televisión les observarán las 24 horas del día y los micrófonos escucharán sus conversaciones en todo momento. Como elemento de tensión, cada concursante debe "nominar" a otros tres para que luego la audiencia decida a quién elimina cada semana. Por último, su subsistencia depende de la realización de distintas pruebas de habilidad que el programa les va exigiendo a lo largo del tiempo. Los concursantes pueden utilizar siempre que lo deseen lo que se denomina «confesionario», lugar donde pueden expresar sus sentimientos o inquietudes a los responsables del programa y, por extensión, a la audiencia.

1.5. Características generales:

1.5.1. Canal emisor: Tele 5, cadena privada española. El formato, propiedad de la productora Zeppelin-Endemol, se emite también en otros países.

1.5.2. Zona de difusión: España.

1.5.3. Lengua de origen: castellano.

1.5.4. Formato: concurso.

1.5.5. Género: realismo.

2. Audiencia: la cuota que alcanzó la primera edición fue realmente espectacular. Millones de espectadores siguieron el desarrollo del concurso, especialmente en momentos clave como las eliminaciones de participantes o el desenlace final. La audiencia incluía personas de todas las edades, desde niños hasta ancianos, y de clases sociales muy diversas. Probablemente ésta es la característica más sobresaliente del producto, un formato que iba acomodando la diversa audiencia según la franja horaria en que se iban emitiendo los distintos fragmentos. 
3. Características formales de imagen y sonido:

3.1. Sonido: no tiene música ambiente ni voz en off. En ocasiones, la producción utiliza música para estimular a los concursantes o para la realización de algunas de las pruebas que deben superar. En todo momento se pueden escuchar las conversaciones de los participantes.

3.2. Imagen: presenta siempre la misma iluminación, de poco contraste. Se ofrece también imagen en horas nocturnas, gracias a las cámaras de infrarrojos.

3.3. Ángulo de la toma y planos: el ángulo de imagen es casi siempre el normal, a la altura de los ojos, y los planos más utilizados son el medio o el general. En muy pocas ocasiones se utiliza el primer plano que, como sabemos, se identifica con la intimidad del personaje. En este producto no existe intimidad, al menos formalmente, y por eso no se utiliza ese plano; incluso en las imágenes del confesionario se utiliza un plano medio.

3.4. Códigos cinemáticos: las cámaras son estáticas, ofreciendo panorámicas que facilitan el seguimiento de los participantes. La profundidad de foco permite que toda la escena sea nítida, igualando en importancia a todos los elementos.

El producto es de difícil clasificación en los géneros televisivos tradicionales por varias razones: es novedoso el hecho de que se pueda seguir continuadamente durante tres meses, así como que existan distintas plataformas alternativas para observarlo: Internet, televisión digital, etc. En cualquier caso, no se puede clasificar como ficción porque no responde a ningún código de ficción establecido y sí a los del realismo, aunque con características singulares que explicaremos a continuación.

El Reality-Show es uno de los últimos géneros que se incorporaron a la televisión. Se nutre de todos los anteriores y construye una nueva categoría que, en realidad, se comporta como un intergénero, precisamente por contar con elementos de todos los demás. Tiene una serie de posibilidades estilísticas que parten, en primer lugar, de la característica de la escenificación (por influencia de la cultura teatral) y esto se produce porque este formato logra construir una nueva relación con los espectadores. En segundo lugar, se caracteriza por la figura de un conductor que, en el caso de Gran Hermano, se deja en manos de una periodista de prestigio, Mercedes Milá, que aparece en el resumen semanal que cuenta con el máximo de audiencia. La tercera característica del Reality es la oralidad como forma de narración y la cuarta, la consideración de los códigos técnicos como parte consustancial de esa construcción. Es todo lo contrario a la cámara indiscreta porque el que participa es consciente de su presencia y, además, está de acuerdo con que la cámara sea su testigo. Es decir, la cámara adquiere un papel activo y mediador en la narración. Este género parte de la idea de espacio nunca abordado por la televisión, lo que llega a sus últimas consecuencias en el caso que estamos analizando. La última característica del Reality, que también aparece en Gran Hermano, es que se trata de un modelo de verdad como material. Tampoco puede olvidarse que en este modelo es imprescindible la incorporación del espectador que se convierte en actor directo. En Gran 
Hermano se traduce en una audiencia activa que decide la expulsión o permanencia de los concursantes y que, además, puede interactuar con la propia difusión técnica (la audiencia de las plataformas digitales puede elegir la cámara a través de la cual desea observar en este nuevo concepto de vouyerismo que ofrece el concurso).

Acabamos de esbozar las características del Reality, un género cuyo origen se remonta a finales de los años sesenta, en las televisiones públicas europeas, que lo crearon como una derivación del género de investigación en casos de sucesos cuyo proceso había quedado inacabado (el primero fue Dossier XY en Canal 1 de Alemania; le siguieron otros como Crime Watch en la BBC inglesa, Psico-show en Francia o Teléfono amarillo en Italia). Esa primera etapa del Reality-Show respondía a la idea de servicio público, pero, tras los años noventa, con la desregulación que aludíamos al principio, se va a plantear como una mediación entre los hechos y los propios protagonistas de los hechos.

En el caso de Gran Hermano se trata de un nuevo Reality en el cual se supone que desaparece, precisamente, el elemento de mediación, para ofrecer simplemente los hechos: la observación inocente de la realidad o la vida en directo tal y como se ha promocionado el producto. En cualquier caso, dejaremos de lado la cuestión terminológica ya que se pueden argumentar objeciones a la catalogación como Reality (o Post-Reality, como nosotros planteamos que se denomine) para centrarnos en lo que consideramos que es la gran falacia, es decir, la observación de la realidad o la verdad. No es irrelevante esta observación, ya que esta cuestión de la verdad o veracidad del espacio ha llevado a situaciones que rozan lo absurdo después de la solicitud de una ponencia en el Senado para determinar el grado de fiabilidad y verosimilitud del programa.

Umberto Eco llama neo-TV a una televisión que ahora no tiene inconveniente en hablar de sí misma. Señala que ha entrado en crisis el concepto de verdad que antes diferenciaba los programas de información de los programas de ficción. La televisión se ha transformado y ha pasado de ser un vehículo de los hechos (entendida como algo neutro que se limita a ofrecer los hechos de la realidad) a un aparato para la producción de los hechos; es decir, ha pasado de ser un espejo de realidad a un productor de la realidad misma (Eco, 1983: 135-152). En lo que llama Eco la paleo-TV no existían los micrófonos ni las cámaras porque la propia televisión intentaba esconder todo ese mecanismo, el artificio técnico se ocultaba expresamente para lograr transmitir esa apariencia de verdad del producto ofrecido a la audiencia. En la neo-TV, por el contrario, no hay nada fingido: vemos a conductores de programa que hablan con realización cuando están en el aire, se nos ofrecen 
imágenes de las cámaras y de los micrófonos; incluso podemos observar cómo el regidor va dirigiendo la acción. Esta nueva televisión muestra todo el sistema técnico, precisamente para demostrar que su existencia no produce mediación alguna sobre el resultado, intento vano porque cualquier espectador debe saber que hasta el directo más formal incluye una selección y por tanto una manipulación (que no necesariamente es malintencionada). La simple elección de una cámara u otra supone elegir un fragmento de la realidad frente a otro y, por tanto, la imagen que se nos ofrece no constituye una realidad completa, sino un punto de vista de esa realidad (Cano, 1999).

Lo que acabamos de exponer, aplicado a Gran Hermano, es de gran importancia para entender porqué consideramos que puede entenderse como obra de ficción - aunque lo sea utilizando los códigos del realismo- directamente emparentada con la representación teatral. La neo-TV llega a su última expresión al mostrar el mecanismo televisivo al desnudo, en lo que se supone tiempo real y en lo que pretende ser una cámara inocente que muestra la verdad sin intervención de ningún tipo.

Los códigos del concurso son los del Reality porque es una realidad la que nos ofrece. Esas personas viven su propia realidad, ya que los tres meses que están encerrados son tres meses de su vida que no recuperarán cuando concluya el concurso. Por tanto, es una realidad en primera instancia. Una realidad, eso sí, creada por el aparato televisivo; que crea un espacio material, crea también unas condiciones de permanencia en ese espacio físico y desarrolla las condiciones que favorecerán la estancia de determinadas personas dentro de ese espacio. Es decir, aunque los personajes están viviendo su propia experiencia, lo cierto es que es una realidad creada por la televisión y, por tanto, una realidad de ficción. Una ficción que, obviamente, cuenta con una trama, unos personajes, un director y unos espectadores. En definitiva, una ficción que constituye el espacio escénico de una obra teatral, aunque utilizando elementos de realidad o, dicho de otra forma, códigos del realismo que son aplicados a la elaboración del contenido semiótico del producto de ficción y que son fundamentalmente la credibilidad, la popularidad, el disfrute del público y la identificación con lo natural.

El producto de ficción es construido con técnicas realistas, especialmente con una puesta en escena que es heredera directa de una cultura de representación y que asume el concepto de audiencia activa, una audiencia que va a interpretar el producto a partir de sus experiencias y que, según algunas investigaciones realizadas, prefiere el realismo al entretenimiento, lo que puede explicar el éxito de un producto como Gran Hermano. Un producto que utiliza la mímesis dramática en sus últimas consecuencias: la realidad se ofrece tal y como se produce, no es narrada o contada, sino que es directa- 
mente mostrada y, por tanto, convertida (la realidad) en elemento semiótico (dotado de significado).

La obra clásica se compone de varios espacios. Hemos de dejar a un lado el primero, el textual (o tipográfico), porque en este producto no nos interesa. Sí nos van a interesar los otros cinco. El espacio teatral de Gran Hermano es un espacio material construido por la televisión: una casa fabricada expresamente, rodeada de un pasillo invisible para el público y para los participantes donde se sitúan numerosas cámaras que, supuestamente, observan la totalidad de ese espacio teatral.

Es, como corresponde, un espacio cerrado dentro del sistema global. Cerrado no sólo metafóricamente, ya que los participantes no lo pueden abandonar, ni modificar, ni transgredir. El espacio escenográfico, formado por los significantes visuales estáticos, coincide en este caso con el teatral, ya que está conformado por la totalidad de la casa. El decorado es la casa completa, toda ella es escenario, escenografía y decorado. De hecho, la propia casa constituye un personaje en sí misma, por la importancia simbólica que posee y eso es lo que la identifica así mismo con el espacio lúdico, constituido por los significantes visuales dinámicos. Éstos están representados por los elementos que la producción va introduciendo en el espacio escenográfico: animales, pruebas, materiales $y$, de forma muy especial, testimonios de la familia, sucesos de la realidad exterior o elementos que han sacudido a la opinión pública. Este espacio lúdico es construido por la producción sin que los concursantes puedan intervenir o discernir si esos elementos son reales o inequívocos, ya que ellos están aislados físicamente de la realidad social (no poseen televisor, ni radio ni periódicos).

El espacio escénico es el más importante en el concurso. Se define por las relaciones dentro/fuera, presencia/ausencia. Todo lo que dicen o hacen los personajes está dentro del espacio escénico, por lo que en Gran Hermano es un continuum, una larga secuencia que no permite que existan sucesos fuera de la escena, sucesos que no entenderíamos al no existir narrador, ni coro, ni texto. Toda la acción es aparente, no hay acción latente en Gran Hermano. También este espacio es cerrado. El espacio escénico es semióticamente neutro, pero se dota de sentido a través del resto de espacios.

El espacio dramático, por último, es el conformado por la representación simbólica, es el que percibe la audiencia. La audiencia observa ese espacio teatral cerrado donde el significado es creado simultáneamente por todos los personajes que desconocen el texto y que de forma individual van construyendo una totalidad, se va dotando de significado para adquirir un valor simbólico, una semiotización. El papel que interpretan los actores es el primer elemento abierto de este sistema teatral, ya que su desarrollo se deja a la 
espontaneidad de los mismos participantes, espontaneidad que tampoco es total como explicaremos ahora. La escenografía se convierte en el propio texto teatral que ni la audiencia ni los actores conocen. El concurso se convierte en un espacio escénico continuo que se concreta en una sola escena, un ámbito físico construido y acotado que es lugar donde adquiere su carácter semiótico.

Esta representación mimética no puede interpretarse como una copia o representación exacta de la realidad desde el momento en que se ha seleccionado un determinado fragmento, dando prioridad a una cosa sobre otra. La primera realidad seleccionada es extrínseca, está fuera del propio concurso -la selección de participantes, la elaboración del espacio material, etc.En cuanto a la selección interna de la realidad mostrada se efectúa cuando se elige una cámara sobre otra, un concursante $u$ otro. No vemos toda la realidad, sino una parte de ella. No es la vida en directo tampoco porque los concursantes son conscientes de la existencia de cámaras y micrófonos y eso produce una mediación técnica de la que son conscientes. La cámara no es inocente y los concursantes tampoco. Mucho menos la producción del espacio que de forma explícita orienta la participación de cada uno, ofreciendo información de forma individual en el confesionario, dándoles fragmentos de la realidad manipulados o sesgados según sus intereses.

De hecho, es fundamental analizar la importancia de esas conversaciones que se producen en el confesionario para orientar la actitud de los personajes en momentos determinados. Así mismo, la repetición, comentario, exaltación o censura de esas mismas actitudes en el resto de programas de la cadena, será lo que logre el cambio de opinión en la misma audiencia que es manipulada todo el tiempo; se ofrecen las imágenes que interesan de forma insistente, se comentan los episodios en mesas redondas y tertulias televisivas, etc. Es elección de la producción el ofrecer unas cámaras u otras, pues es evidente que existen puntos ciegos al ojo catódico dentro de la casa —situación que conocen los concursantes - y que, en realidad, no se emite todo el material que se recoge. Incluso, ha habido situaciones de gran interés que la audiencia nunca ha conocido (escapadas al exterior o conversaciones con los cámaras a quienes pueden ver al trasluz).

Tampoco es inocente la elección de personajes, ni es casualidad que las emisiones, simultáneas o no, en otros países presenten las mismas situaciones: bodas exóticas, expulsión de algunos participantes, elección de personas con pasados escandalosos o pintorescos, etc. Gran Hermano es una obra de teatro con personajes, guión, director y espacios escénicos. Lo que ocurre es que presenta características singulares; una de ellas es que los propios personajes desconocen el guión en el que están participando. Ese guión, así 
mismo, se va modificando según los acontecimientos y, sobre todo, según la audiencia. Cuando, en la segunda edición del concurso, un participante es violento con quien tiene una relación sentimental, no se le recrimina hasta que la opinión pública se enfurece. Tampoco entonces se toma una decisión inmediata, sino que se crea una situación tensa que permite elevar los índices de audiencia al máximo. Sólo en ese momento se decide que debe ser expulsado y se hace de la forma que más rendimiento produce.

La selección de participantes, es decir, el casting de los actores es lo fundamental. Y el texto, que sólo conoce la producción y que se elabora interactuando con los propios concursantes, es el que define la relación con la audiencia. La primera edición de Gran Hermano obtuvo unos índices nunca vistos, índices que no se han repetido ni con los remakes (El Bus, Supervivientes y otros experimentos de cariz pornográfico que se han desarrollado en algunos países), ni con su secuelas.

Dejando a un lado el elemento novedoso de la primera vez, es evidente el giro que los productores han realizado en la segunda entrega, lo que les ha costado gran parte de audiencia. En la primera edición, se buscaron personajes distintos entre sí (en edad, clase social, intereses, situación familiar, etc.) y la solidaridad que apareció en el grupo favoreció el famoso pacto: la negativa a nominar a ningún compañero, dejando la responsabilidad de expulsar a los participantes en manos de la audiencia. Se creó entonces una relación dialéctica que favorecía toda la trama: conspiración, diplomacia, diálogo, estrategia, etc. Esa dialéctica fue la que interesó a un público heterogéneo que no tenía gran interés en observar situaciones morbosas o de contenido sexual y que se identificó con sus héroes, tal y como pretendía la tragedia clásica, que sufrían con cada nominación y con cada expulsión de concursantes, llegando a movilizaciones ciudadanas de gran interés sociológico y castigando implacablemente a los participantes que se apartaban de la solidaridad grupal, siendo expulsados inmediatamente por la audiencia.

Sorprendentemente, la producción ha cambiado en la segunda edición, buscando personajes más jóvenes y atractivos, con un potencial sexual mucho mayor, lo que favorece la creación de parejas sentimentales o sexuales. Esto ha aburrido al público que, como en el caso de El Bus, no tiene mayor interés en seguir las actividades de personajes que parecen adolescentes en un campamento de verano, cuya actividad intelectual es casi nula (apenas mantienen conversaciones entre sí y la mayor parte del día transcurre dormitando) y de quienes se ofrecen escenas no aptas para todos los públicos. Lógicamente la expectación sentimental dura poco tiempo y el interés decae, mientras que la difusión de imágenes no toleradas ofrece un elemento morboso al principio, pero que carece de interés en su repetición y, lo que es 
más importante, imágenes que a la audiencia no le apetece visualizar en cualquier horario. Si para nosotros fue tan evidente que $E l B u s$ no iba a tener audiencia, no se puede entender que se hayan incorporado muchos de sus elementos al producto Gran Hermano, incluso después de comprobar que la receta no había funcionado. De hecho, su calado social ha sido nulo. Frente a los personajes de Gran Hermano, conocidos e integrados en la vida social como otros personajes de una serie televisiva de éxito, los participantes de $E l$ $B u s$ no sólo son desconocidos, sino que ni siquiera sabemos el nombre del ganador. Y eso a pesar de que la cadena que lo programó, Antena 3, siguió la misma estrategia de apoyo en programas de máxima difusión y resúmenes continuos a lo largo de toda la semana.

De todas formas, si alguien duda de la existencia de una trama teatral, dirigida desde fuera de la casa de Gran Hermano, basta con reflexionar sobre lo siguiente: no puede ser casual la constatación de que durante tres meses diez o doce personas jamás hablan de inquietudes intelectuales, sociales o políticas - salvo contadas, y polémicas, excepciones-. A pesar de contar con personajes que en su vida real se desenvuelven en distintas situaciones, lo cierto es que nadie habla del desempleo, de la sexualidad, mucho menos de política o religión... ¿eso es la vida en directo? ¿en la vida real nadie reflexiona sobre las inquietudes humanas, personales o sociales? Es evidente que el aparato televisivo nos hurta, de forma activa (eliminando las cámaras que lo recogen) o pasiva (orientando la opinión de los actores), este tipo de situaciones. Probablemente los propios concursantes no desean ser catalogados porque eso puede favorecer su expulsión, pero la razón última se debe a la falta de interés en que el propio programa sea definido políticamente, lo que puede influir en la audiencia y, sobre todo, en los anunciantes y publicistas. No es la realidad lo que ofrece Gran Hermano, sino un espectáculo teatral que incorpora elementos reales como novedad.

\section{Referencias bibliográficas}

Bueno, G. (2000). Televisión. Apariencia y verdad. Barcelona: Gedisa.

CANo, P. L. (1999). De Aristóteles a Woody Allen. Poética y retórica para cine y televisión. Barcelona: Gedisa.

ECO, U. (1983). Viagem na irrealidade quotidiana. Lisboa: Cosmos.

LEDO, M. (1987). «Xohana Torres e os media». Festa da palabra silenciada, 5.

RAMONET, I. (2000). La golosina visual. Madrid: Debate.

VILCHES, L. (1993). La televisión. Los efectos del bien y del mal. Barcelona: Paidós. 